\title{
Diffuse large B-cell lymphomas with germinal center B-cell-like differentiation immunophenotypic profile are associated with high apoptotic index, high expression of the proapoptotic proteins bax, bak and bid and low expression of the antiapoptotic protein bcl-xl
}

Maria Bai ${ }^{1}$, Angelos Skyrlas ${ }^{1}$, Niki John Agnantis ${ }^{1}$, Sevasti Kamina ${ }^{1}$, Elena Tsanou ${ }^{1}$, Constantina Grepi ${ }^{1}$, Vassiliki Galani ${ }^{2}$ and Panagiotis Kanavaros ${ }^{2}$

${ }^{1}$ Department of Pathology and ${ }^{2}$ Department of Anatomy-Histology-Embryology, Medical Faculty, University of Ioannina, Ioannina, Greece

The aim of this study was to analyze the relations between differentiation immunophenotypes and the status of apoptosis and proliferation in diffuse large B-cell lymphomas. Therefore, the bcl6/CD10/MUM1/CD138 differentiation immunophenotypic profiles were studied in relation to (a) the apoptotic index, (b) the apoptosis-associated bcl2 family proteins bcl2, bcl-xl, bax, bak, bad and bid, (c) the proliferation index (Ki67) and (d) the cell cycle proteins cyclin A, cyclin B1, cyclin D3, cyclin E, p53, Rb, p16 and p27 in 79 cases of diffuse large B-cell lymphomas. Two major differentiation immunophenotypic profiles were distinguished: the germinal center B-cell-like profile; 31 cases (bcl6+/CD10 $\pm /$ MUM1-/CD138-: 29 cases and bcl6-/CD10+/MUM1-I CD138-: two cases) and the nongerminal center B-cell-like profile (bcl6 $\pm / C D 10-/ M U M 1+/ C D 138-)$; 48 cases. The expression of bax, bak and bid and the apoptotic index were significantly higher in the germinal center Bcell-like profile than in the nongerminal center $\mathrm{B}$-cell-like profile $(P=0.045,0.018,0.003$ and 0.034 , respectively). In contrast, the expression of bcl-xl was significantly lower in the germinal center B-cell-like profile than in the nongerminal center $B$-cell-like profile $(P=0.026)$. The expression of bcl6 and CD10 showed significant positive correlation with the expression of bax $(r=0.659, P<0.001$ and $r=0.240, P=0.033$, respectively), bak $(r=0.391$, $P<0.001$ and $r=0.233, P=0.039$, respectively) and bid $(r=0.652, P<0.001$ and $r=0.238, P=0.035$, respectively) and significant negative correlation with the expression of bcl-xl $(r=-0.536, P<0.001$ and $r=-0.250, P=0.029$, respectively). The expression of MUM1 showed significant negative correlation with the expression of bax $(r=-0.276, P=0.014)$ and bid $(r=-0.266, P=0.018)$ and significant positive correlation with the expression of $\mathrm{bcl}-\mathrm{xl}(r=0.238, P=0.037)$. The above findings indicate that diffuse large $\mathrm{B}$-cell lymphomas with germinal center B-cell-like immunophenotypic profile are associated with increased apoptosis status, high expression of the proapoptotic proteins bax, bak and bid and low expression of the antiapoptotic protein bcl-xl.

Modern Pathology (2004) 17, 847-856, advance online publication, 9 April 2004; doi:10.1038/modpathol.3800130

Keywords: Bcl6; CD10; MUM1; CD138; apoptosis; cell cycle; diffuse large B-cell lymphomas

Diffuse large B-cell lymphomas represent the most common type of non-Hodgkin's lymphomas in Western countries and are characterized by hetero-

Correspondence: Dr M Bai, MD, PhD, Department of Pathology, Medical School, University of Ioannina, Ioannina 45110, Greece. E-mail: mbai@cc.uoi.gr

Received 2 February 2004; revised and accepted 1 March 2004; published online 9 April 2004 geneous clinical, immunophenotypic and genetic features. ${ }^{1-7}$ There is accumulating evidence that diverse mechanisms resulting in the deregulation of cell cycle and apoptotic pathways are involved in the pathogenesis of diffuse large B-cell lymphomas. ${ }^{3-6}$

Recently, the global gene expression profile of diffuse large B-cell lymphomas was analyzed by CDNA $^{8-10}$ and oligonucleotide microarrays. ${ }^{11}$ Alizedeh et $a l^{8}$ identified two molecularly distinct 
groups of diffuse large B-cell lymphomas, the germinal center B-cell-like and the activated B-celllike diffuse large B-cell lymphomas. This was confirmed by Rosenwald et $a l^{9}$ who, in addition to the two gene expression groups, also described the type 3 diffuse large B-cell lymphomas. The germinal center B-cell-like diffuse large B-cell lymphomas were characterized by the expression of genes of the normal germinal center $\mathrm{B}$ cells (eg bcl6, CD10, CD38), the activated B-cell-like diffuse large B-cell lymphomas were characterized by the expression of genes that are normally induced during in vitro activation of peripheral blood B cells and the type 3 diffuse large B-cell lymphomas did not express either set of genes at a high level. ${ }^{8-10}$ The gene expression signature of the activated B-cell-like diffuse large B-cell lymphomas included a gene that is translocated in lymphoid malignancies, IRF4 (MUM1/LSIRF), antiapoptotic genes such as FLIP and $b c l 2$ and a subset of the genes that are characteristic of plasma cells. ${ }^{8-10}$ The patients with germinal center B-cell-like diffuse large B-cell lymphomas had more favorable clinical outcome than those with activated B-cell-like or type 3 diffuse large B-cell lymphomas. ${ }^{8-10}$

Since the cDNA and oligonucleotide microarrays technology is not generally available, many studies investigated the immunohistochemical expression of B-cell differentiation antigens (eg bcl6, CD10, MUM1, CD138) in diffuse large B-cell lymphomas and some of them correlated the differentiation immunophenotypes with clinical data. ${ }^{12-32}$ Importantly, in one of these studies, Hans et al, ${ }^{32}$ showed that the classification of diffuse large B-cell lymphomas into germinal center and nongerminal center B-cell-like groups based on the bcl6/CD10/ MUM1 differentiation immunophenotypes is prognostically relevant and predicts the cDNA classification in $71 \%$ of germinal center B-cell-like and $88 \%$ of activated B-cell-like or type 3 diffuse large B-cell lymphomas. On the other hand, the expression of bcl6 and CD10 was associated with increased apoptosis and proliferation in cell lines and lymphoid malignancies. ${ }^{33-40}$ In this respect, we recently showed that increased expression of bcl6 and CD10 is associated with increased apoptosis and proliferation in diffuse large B-cell lymphomas. ${ }^{41}$ However, to the best of our knowledge, little is known about the relations between the bcl6/CD10/MUM1/ CD138 differentiation immunophenotypes and the status of apoptosis and proliferation in these lymphomas. In addition, although the immunohistochemical expression of the apoptosis-associated bcl2 family proteins, bcl2, bax, bak and mcl1 was reported in diffuse large B-cell lymphomas, ${ }^{16,18,20,21,27,42-50}$ the expression levels of bcl-xl, bad and bid proteins and their relations with the status of apoptosis and proliferation were not extensively analyzed in these lymphomas. Therefore, the bcl6/CD10/MUM1/CD138 differentiation immunophenotypic profiles were studied in rela- tion to (a) the apoptotic index, (b) the apoptosisassociated proteins bcl2, bcl-xl, bax, bak, bad and bid, (c) the proliferation index (Ki67) and (d) the cell cycle proteins cyclin A, cyclin B1, cyclin D3, cyclin $\mathrm{E}, \mathrm{p} 53, \mathrm{Rb}, \mathrm{p} 16$ and p27 in 79 cases of diffuse large B-cell lymphomas.

\section{Materials and methods}

\section{Materials}

In all, 79 cases of de novo diffuse large B-cell lymphomas ( 37 nodal and 42 extranodal) classified according to the WHO classification ${ }^{1}$ were selected from the files of the Department of Pathology of the University of Ioannina on the basis that complete clinicopathological parameters were available.

\section{Immunohistochemistry}

Immunostainings were performed on formalinfixed, paraffin-embedded tissue sections by the labelled streptavidin-avidin-biotin method using monoclonal antibodies directed against CD138 (dilution 1:10, clone AM411-10 M, BioGenex, CA, USA), bcl-xl (dilution 1:25, clone 2H11, Zymed, South San Francisco CA, USA) and bad (dilution 1:40, clone sc-8044, Santa Cruz, CA, USA). In addition, the following polyclonal antibodies were used: bax (dilution 1:40, code A3533, Dako SA, Glostrup, Denmark), bak (dilution 1:40, code A3538, Dako SA, Glostrup, Denmark), bid (dilution 1:40, clone sc-11423, Santa Cruz, CA, USA) and IRF-4/MUM1 (dilution 1:40, clone sc-6059, Santa Cruz, CA, USA). Pretreatment of the sections with $10 \mathrm{mM}$ sodium citrate buffer ( $\mathrm{pH}$ 6.0) in a microwave oven was performed. The monoclonal antibodies directed against bcl6, CD10, bcl2, Ki67, cyclin A, cyclin B1, cyclin D3, cyclin E, p53, Rb1, p16 and p27 proteins, the corresponding positive controls and the counting approach for the expression status of these proteins were reported in detail previously. ${ }^{41,51,52}$ The same approach was used for the counting of MUM1, CD138, bax, bak, bad, bid and bcl-xl immunopositive cells. Briefly, a continuous score system was adopted by using the $\times 40$ objective lens and counting at least 10 fields selected on the basis that they contained immunopositive cells. The number of immunopositive cells was divided by the total number of the counted cells and the expression was defined as the percentage of positive cells in the total number of the counted cells. Positive expression for MUM1 and CD138 proteins was considered when at least $25 \%$ of neoplastic cells were immunopositive according to previous criteria. $^{12}$ The bcl6/CD10/MUM1/CD138 immunophenotypes and their assignment to germinal center or nongerminal center B-cell-like profiles were determined taking into consideration previous criteria. ${ }^{32}$ Positive expression for bcl-xl, bax, bak, 
bad and bid proteins was considered when at least $10 \%$ of neoplastic cells were immunopositive. Reactive lymph nodes and normal thymuses from our previous studies were used as positive controls. ${ }^{41,51,52}$ Negative controls were included and consisted in the same immunohistochemical method with omission of the primary antibody.

\section{Statistical Analysis}

Mann-Whitney test, $\chi^{2}$ tests, Spearman's correlation coefficient test and analysis of variance were used for statistical analysis. The results were considered as statistically significant when $P<0.05$. The program SPSS for Windows Release 10 was used for statistical analysis.

\section{Results}

Immunohistochemical expression of MUM1, CD138, bax, bak, bad, bid and bcl-xl proteins was found in 48/79 (60\%), 0/79 (0\%), 73/79 (92\%), 41/79 (52\%), 60/79 (76\%), 44/79 (56\%) and 46/77 (60\%) cases, respectively (Figure 1) (Table 1). High expression status of bax, bak, bad, bid and bcl-xl proteins (at least $25 \%$ of neoplastic cells immunopositive) was found in 36/79 (46\%), 20/79 (26\%), 25/79 (32\%), $30 / 79(38 \%)$ and $46 / 77(60 \%)$ cases, respectively.

The immunohistochemical expression of bcl6, CD10, bcl2, cyclin A, cyclin B1, cyclin D3, cyclin $\mathrm{E}, \mathrm{p} 53, \mathrm{Rb}, \mathrm{p} 16$ and $\mathrm{p} 27$ proteins, the proliferation index (as assessed by the Ki67 staining) and the apoptotic index (as assessed by the TUNEL method) were reported in detail previously. ${ }^{41,51,52}$

\section{Differentiation Immunophenotypic Profiles}

Two major immunophenotypic profiles were distinguished according to the pattern of differentiation: (a) the germinal center B-cell-like differentiation immunophenotypic profile; 31 cases (bcl6+/ CD10 + /MUM1-/CD138-: 26 cases, bcl6+/ CD10-/MUM1-/CD138-: three cases and bcl6-/ CD10 +/MUM1-/CD138-: two cases) and (b) the nongerminal center B-cell-like differentiation immunophenotypic profile; 48 cases (bcl6 + /CD10-/ MUM1 +/CD138-: 24 cases and bcl6-/CD10-/ MUM1 + /CD138-: 24 cases) (Table 2).

\section{Relations between the Two Major Differentiation Immunophenotypic Profiles and Apoptotic Index, Proliferation Index, bcl2 Family Proteins and Cell Cycle Proteins}

The Mann-Whitney test was used to analyze the two major bcl6/CD10/MUM1/CD138 differentiation immunophenotypic profiles in relation to the apoptotic index, the proliferation index (Ki67) and the expression levels of bcl2 family proteins and cell cycle proteins (Table 3). The germinal center B-celllike profile, compared to the nongerminal center B-cell-like profile, was significantly associated with higher apoptotic index $(P=0.034)$, higher expression of bax $(P=0.045)$, bak $(P=0.018)$ and bid $(P=0.003)$ proteins and lower expression of bcl-xl protein $(P=0.026)$ (Table 3$)$. No significant correlations were found between the two major bcl6/CD10/ MUM1/CD138 differentiation immunophenotypic profiles and the expression levels of bcl2, bad,
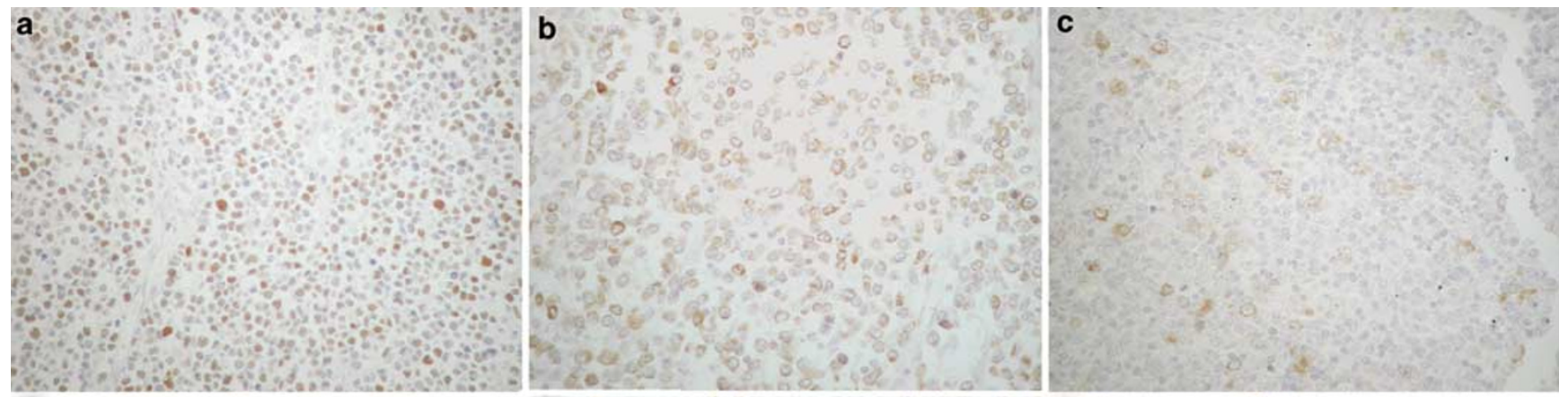

d
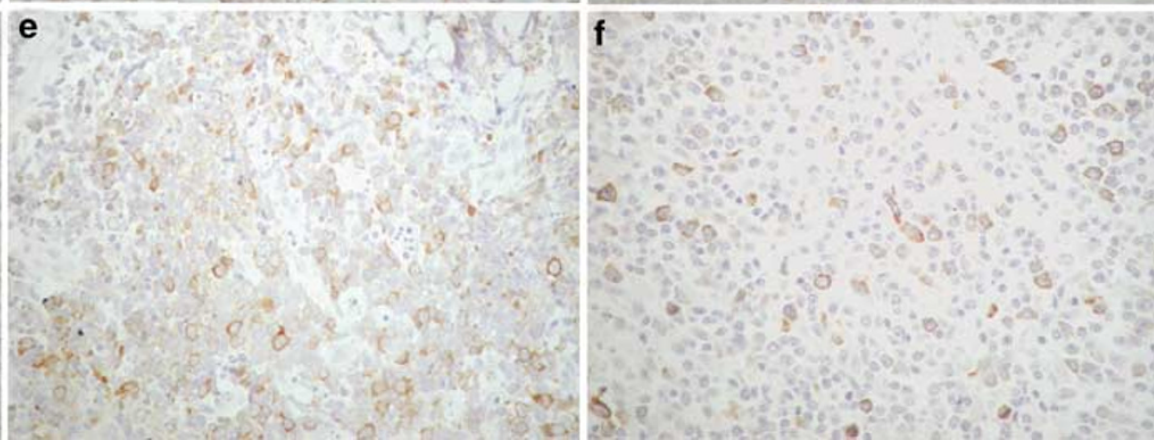

Figure 1 Immunohistochemical expression of (a) MUM1, (b) Bax, (c) Bak, (d) Bad, (e) Bid and (f) Bcl-xl in neoplastic cells of diffuse large B-cell lymphomas (magnification $\times 400$ ). 
Table 1 Expression of MUM1, CD138, bax, bak, bad, bid and bcl-xl proteins

\begin{tabular}{lc}
\hline Proteins & Positive cases/total number of cases \\
\hline MUM1 & $48 / 79(60 \%)$ \\
CD138 & $0 / 79(0 \%)$ \\
bax & $73 / 79(92 \%)$ \\
bak & $41 / 79(52 \%)$ \\
bad & $60 / 79(76 \%)$ \\
bid & $44 / 79(56 \%)$ \\
bcl-xl & $46 / 77(60 \%)$
\end{tabular}

Positive expression for MUM1 and CD138 proteins was considered when at least $25 \%$ of neoplastic cells were immunopositive. Positive expression for bcl-xl, bax, bak, bad and bid proteins was considered when at least $10 \%$ of neoplastic cells were immunopositive.

Table 2 Bcl6/CD10/MUM1/CD138 differentiation immunophenotypic profiles

\begin{tabular}{lc}
\hline Differentiation immunophenotypic profiles & Number of cases \\
\hline $\begin{array}{l}\text { Germinal center B-cell-like profile } \\
\text { bcl6+/CD10+/MUM1-/CD138- } \\
\text { bcl6+/CD10-/MUM1-/CD138- }\end{array}$ & $26(33 \%)$ \\
bcl6-/CD10+/MUM1-/CD138- & $3(4 \%)$ \\
Total cases & $2(3 \%)$ \\
& $31 / 79(40 \%)$ \\
Nongerminal center B-cell-like profile & \\
bcl6+/CD10-/MUM1+/CD138- & \\
bcl6-/CD10-/MUM1+/CD138- & $24(30 \%)$ \\
Total cases & $24(30 \%)$ \\
\hline
\end{tabular}

Ki67, cyclin A, cyclin B1, cyclin D3, cyclin E, p53, $\mathrm{Rb}, \mathrm{p} 16$ and p27 proteins (Table 3). The basic statistical data (mean values, standard deviation, standard error, range) for the expression levels of the bcl2 family proteins and for the values of the apoptotic index in relation to the two major bcl6/ CD10/MUM1/CD138 differentiation immunophenotypic profiles are presented in Table 4 . The relations between the expression of bcl2 family proteins (positive vs negative cases) and the two major bcl6/CD10/MUM1/CD138 differentiation immunophenotypic profiles are presented in Table 5.

The $\chi^{2}$ tests were used to analyze the two major bcl6/CD10/MUM1/CD138 differentiation immunophenotypic profiles in relation to the expression status (high- vs low-expression status) of bcl2 family proteins, cell cycle proteins and the proliferation index (Ki67). The germinal center B-cell-like profile was significantly associated with high-expression status of bak $(P=0.036)$ and bid $(P=0.001)$ proteins and low expression status of bcl-xl protein $(P=0.031) \quad$ (Table 6). No significant correlations were found between the two major bcl6/CD10/ MUM1/CD138 differentiation immunophenotypic profiles and the expression status (high- vs lowexpression status) of bcl2, bax, bad, Ki67, cyclin A,
Table 3 Differentiation immunophenotypic profiles in relation to the apoptotic index (AI), proliferation index (PI) and the expression of bcl2 family and cell cycle proteins (Mann-Whitney test)

\begin{tabular}{|c|c|c|c|c|}
\hline & $\begin{array}{l}\text { Differentiation } \\
\text { profile }\end{array}$ & $\begin{array}{l}\text { Number } \\
\text { of cases }\end{array}$ & Mean rank & $P$-values \\
\hline \multirow[t]{2}{*}{ P53 } & 1 & 31 & 35.16 & 0.129 \\
\hline & 2 & 48 & 43.13 & \\
\hline \multirow[t]{2}{*}{$\mathrm{Rb}$} & 1 & 31 & 42.17 & 0.396 \\
\hline & 2 & 48 & 38.25 & \\
\hline \multirow[t]{2}{*}{ P16 } & 1 & 31 & 43.60 & 0.255 \\
\hline & 2 & 48 & 37.28 & \\
\hline \multirow[t]{2}{*}{ P27 } & 1 & 31 & 41.02 & 0.711 \\
\hline & 2 & 48 & 39.34 & \\
\hline \multirow[t]{2}{*}{ PI (Ki67) } & 1 & 31 & 42.98 & 0.351 \\
\hline & 2 & 48 & 38.07 & \\
\hline \multirow[t]{2}{*}{ Cyclin A } & 1 & 31 & 37.19 & 0.381 \\
\hline & 2 & 48 & 41.81 & \\
\hline \multirow{2}{*}{ Cyclin B1 } & 1 & 31 & 43.48 & 0.277 \\
\hline & 2 & 48 & 37.75 & \\
\hline \multirow[t]{2}{*}{ Cyclin D3 } & 1 & 31 & 38.10 & 0.548 \\
\hline & 2 & 48 & 41.23 & \\
\hline \multirow{2}{*}{ Cyclin E } & 1 & 31 & 39.77 & 0.934 \\
\hline & 2 & 48 & 40.15 & \\
\hline \multirow[t]{2}{*}{ bcl2 } & 1 & 30 & 37.03 & 0.709 \\
\hline & 2 & 46 & 39.46 & \\
\hline \multirow[t]{2}{*}{ bax } & 1 & 31 & 46.32 & $0.045^{*}$ \\
\hline & 2 & 48 & 35.92 & \\
\hline \multirow[t]{2}{*}{ bak } & 1 & 31 & 47.48 & $0.018^{*}$ \\
\hline & 2 & 48 & 35.17 & \\
\hline \multirow[t]{2}{*}{ bid } & 1 & 31 & 49.50 & $0.003^{*}$ \\
\hline & 2 & 48 & 33.86 & \\
\hline \multirow[t]{2}{*}{ bad } & 1 & 31 & 44.02 & 0.203 \\
\hline & 2 & 48 & 37.41 & \\
\hline \multirow[t]{2}{*}{ bcl-xl } & 1 & 30 & 32.02 & $0.026^{*}$ \\
\hline & 2 & 47 & 43.46 & \\
\hline \multirow[t]{2}{*}{ AI } & 1 & 26 & 37.21 & $0.034^{*}$ \\
\hline & 2 & 36 & 27.38 & \\
\hline
\end{tabular}

Differentiation profile 1: germinal center B-cell-like immunophenotypic profile (bcl6+/CD10+/MUM1-/CD138-: 26 cases, bcl6+/ CD10-/MUM1-/CD138-: three cases and bcl6-/CD10+/MUM1-/ CD138-: two cases; total 31 cases).

Differentiation profile 2: nongerminal center B-cell-like immunophenotypic differentiation profile (bcl6+/CD10-/MUM1+/CD138-: 24 cases and bcl6-/CD10-/MUM1+/CD138-: 24 cases; total 48 cases). ${ }^{*}$ indicates the statistically significant correlations $(P<0.05)$.

cyclin B1, cyclin D3, cyclin E, p53, Rb, p16 and p27 proteins (data not shown).

\section{Relations between bcl6, CD10 and MUM1 Proteins and bcl2 Family Proteins}

The Spearman correlation coefficient test (for assessment of correlation between two continuous variables) was used to analyze the relations of bcl6, CD10 and MUM1 proteins with bcl2 family proteins and the relations between MUM1, proliferation index and apoptotic index (Table 7). The relations between bcl6, CD10, proliferation index and apoptotic index were reported previously. ${ }^{41}$ The positive or negative sign of the Spearman correlation coefficient $r$ in Table 7 expresses significant $(P<0.05)$ or nonsignificant $(P=0.05$ or $P>0.05)$ positive or 
Table 4 Differentiation immunophenotypic profiles in relation to the apoptotic index (AI) and the expression levels of bcl2 family proteins (analysis of variance)

\begin{tabular}{|c|c|c|c|c|c|c|c|c|}
\hline & Differentiation profile & $N$ & Mean value & s.d. & s.e. & Minimum value & Maximum value & $P$-values \\
\hline \multirow[t]{2}{*}{ bax } & 1 & 31 & 27.2581 & 20.8901 & 3.7519 & 5.00 & 80.00 & $0.013^{*}$ \\
\hline & 2 & 48 & 17.9583 & 11.5260 & 1.6636 & 5.00 & 70.00 & \\
\hline \multirow[t]{2}{*}{ bak } & 1 & 31 & 17.4516 & 13.4680 & 2.4189 & 1.00 & 50.00 & $0.009 *$ \\
\hline & 2 & 48 & 10.5417 & 9.4147 & 1.3588 & 1.00 & 50.00 & \\
\hline \multirow[t]{2}{*}{ bad } & 1 & 31 & 14.7742 & 7.0318 & 1.2629 & 1.00 & 25.00 & 0.193 \\
\hline & 2 & 48 & 12.5833 & 7.3740 & 1.0643 & 1.00 & 30.00 & \\
\hline \multirow[t]{2}{*}{ bid } & 1 & 31 & 24.7419 & 17.5612 & 3.1541 & 1.00 & 60.00 & $0.001^{*}$ \\
\hline & 2 & 48 & 12.8125 & 12.9740 & 1.8726 & 1.00 & 60.00 & \\
\hline \multirow[t]{2}{*}{ bcl-xl } & 1 & 30 & 21.9667 & 27.3590 & 4.9950 & 0 & 80.00 & $0.020^{*}$ \\
\hline & 2 & 47 & 38.1277 & 30.2587 & 4.4136 & 0 & 100.00 & \\
\hline \multirow[t]{2}{*}{ bcl2 } & 1 & 30 & 47.0000 & 43.7981 & 7.9964 & 0 & 100.00 & 0.938 \\
\hline & 2 & 47 & 46.2128 & 42.2790 & 6.1670 & 0 & 100.00 & \\
\hline \multirow[t]{2}{*}{ AI } & 1 & 26 & 3.4895 & 2.3971 & 0.4701 & 0.34 & 9.70 & $0.018^{*}$ \\
\hline & 2 & 36 & 2.2983 & 1.4377 & 0.2396 & 0.26 & 6.13 & \\
\hline
\end{tabular}

$\mathrm{N}$, number of cases.

Differentiation profile 1: germinal center B-cell-like immunophenotypic profile (bcl6+/CD10+/MUM1-/CD138-: 26 cases, bcl6+/CD10-/ MUM1-/CD138-: three cases and bcl6-/CD10+/MUM1-/CD138-: two cases; total 31 cases).

Differentiation profile 2: nongerminal center B-cell-like immunophenotypic differentiation profile (bcl6+/CD10-/MUM1+/CD138-: 24 cases and bcl6-/CD10-/MUM1+/CD138-: 24 cases; total 48 cases).

*indicates the statistically significant correlations $(P<0.05)$.

Table 5 Differentiation immunophenotypic profiles in relation to the expression of bcl2 family proteins (positive vs negative cases)

\begin{tabular}{lcc}
\hline & $\begin{array}{c}\text { Differentiation } \\
\text { profile }\end{array}$ & $\begin{array}{c}\text { Differentiation } \\
\text { profile 2 }\end{array}$ \\
\hline bax positive & 29 & 44 \\
bax negative & 2 & 4 \\
bak positive & 20 & 21 \\
bak negative & 11 & 27 \\
bid positive & 23 & 21 \\
bid negative & 8 & 27 \\
bad positive & 25 & 35 \\
bad negative & 6 & 13 \\
bcl-xl positive & 13 & 33 \\
bcl-xl negative & 17 & 14 \\
bcl2 positive & 18 & 29 \\
bcl2 negative & 12 & 18 \\
\end{tabular}

Differentiation profile 1: germinal center B-cell-like immunophenotypic profile (bcl6+/CD10+/MUM1-/CD138-: 26 cases, bcl6+/ CD10-/MUM1-/CD138-: three cases and bcl6-/CD10+/MUM1-/ CD138-: two cases; total 31 cases).

Differentiation profile 2: nongerminal center B-cell-like immunophenotypic differentiation profile (bcl6+/CD10-/MUM1+/CD138-: 24 cases and bcl6-/CD10-/MUM1+/CD138-: 24 cases; total 48 cases).

Positive expression for bcl-xl, bcl2, bax, bak, bad and bid proteins was considered when at least $10 \%$ of neoplastic cells were immunopositive.

negative correlations between two continuous variables. The following significant correlations were found: (a) the expression of bcl6 protein showed significant positive correlation with the expression of bax $(r=0.659, P<0.001)$, bak $(r=0.391, P<0.001)$ and bid $(r=0.652, P<0.001)$ proteins and significant negative correlation with the expression of bcl-xl protein $(r=-0.536, P<0.001)$, (b) the expression of CD10 protein showed significant positive correlation with the expression of bax $(r=0.240$, $P=0.033)$, bak $(r=0.233, \quad P=0.039) \quad$ and bid
Table 6 Differentiation immunophenotypic profiles in relation to the expression status of bcl2 family proteins (high vs low the expression status) ( $\chi^{2}$ tests)

\begin{tabular}{lccc}
\hline & $\begin{array}{c}\text { Differentiation } \\
\text { profile }\end{array}$ & $\begin{array}{c}\text { Differentiation } \\
\text { profile } 2\end{array}$ & P-values \\
\hline bcl2 high & 18 & 29 & 0.881 \\
bcl2 low & 12 & 18 & 0.184 \\
bax high & 17 & 19 & \\
bax low & 14 & 29 & $0.036^{*}$ \\
bak high & 12 & 8 & $0.001^{*}$ \\
bak low & 19 & 40 & \\
bid high & 19 & 11 & 0.278 \\
bid low & 12 & 13 & $0.031^{*}$ \\
bad high & 12 & 35 & \\
bad low & 19 & 33 & \\
bcl-xl high & 13 & 14 & \\
bcl-xl low & 17 & &
\end{tabular}

Differentiation profile 1: germinal center B-cell-like immunophenotypic profile (bcl6+/CD10+/MUM1-/CD138-: 26 cases, bcl6+/ CD10-/MUM1-/CD138-: three cases and bcl6-/CD10+/MUM1-/ CD138-: two cases; total 31 cases).

Differentiation profile 2: nongerminal center B-cell-like immunophenotypic differentiation profile (bcl6+/CD10-/MUM1+/CD138-: 24 cases and bcl6-/CD10-/MUM1+/CD138-: 24 cases; total 48 cases). High-expression status of bcl2 family proteins: at least $25 \%$ of neoplastic cells immunopositive.

Low-expression status of bcl2 family proteins: less than $25 \%$ of neoplastic cells immunopositive.

*indicates the statistically significant correlations $(P<0.05)$.

$(r=0.238, P=0.035)$ proteins and significant negative correlation with the expression of bcl-xl protein $(r=-0.250, P=0.029)$ and (c) the expression of MUM1 protein showed significant negative correlation with the expression of bax $(r=-0.276$, $P=0.014)$ and bid $(r=-0.266, P=0.018)$ proteins and significant positive correlation with the expression of bcl-xl protein $(r=0.238, P=0.037)$ (Table 7$)$. 
Table 7 Correlations between bcl6, CD10 and MUM1 proteins and bcl2 family proteins (Spearman's correlation test)

\begin{tabular}{llllll}
\hline & \multicolumn{1}{c}{ bax } & bak & bid & bad & bcl2 \\
\hline bcl6 & $r=0.659$ & $r=0.391$ & $r=0.652$ & $r=0.118$ & $r=-0.207$ \\
& $P<0.001^{*}$ & $P<0.001^{*}$ & $P<0.001^{*}$ & $P=0.299$ & $P=0.070$ \\
CD10 & $r=0.240$ & $r=0.233$ & $r=0.238$ & $r=0.053$ & $r=-0.056$ \\
& $P=0.033^{*}$ & $P=0.039^{*}$ & $P=0.035^{*}$ & $P=0.640$ & $P=0.627$ \\
MUM1 & $r=-0.276$ & $r=-0.193$ & $r=-0.266$ & $r=-0.115$ & $r=0.050$ \\
& $P=0.014^{*}$ & $P=0.089$ & $P=0.018^{*}$ & $P=0.312$ & $P=0.0 .250$ \\
& & & & $P=0.029^{*}$ \\
\end{tabular}

$r$, Spearman's correlation coefficient. The positive or negative sign of the Spearman's correlation coefficient $r$ expresses significant $(P<0.05)$ or nonsignificant $(P=0.05$ or $P>0.05)$ positive or negative correlations between two continuous variables.

*indicates the statistically significant correlations $(P<0.05)$.

Table 8 Correlations between bcl2 family proteins, apoptotic index (AI) and proliferation index (PI) (Spearman's correlation test)

\begin{tabular}{|c|c|c|c|c|c|c|c|c|}
\hline & $\operatorname{bax}$ & bak & bid & bad & bcl2 & $b c l-x l$ & $A I$ & PI \\
\hline \multirow[t]{2}{*}{ bax } & & $r=0.311$ & $r=0.364$ & $r=0.224$ & $r=-0.207$ & $r=-0.437$ & $r=0.146$ & $r=0.207$ \\
\hline & & $P=0.005^{*}$ & $P=0.001^{*}$ & $P=0.047^{*}$ & $P=0.070$ & $P<0.001^{*}$ & $P=0.258$ & $P=0.068$ \\
\hline \multirow[t]{2}{*}{ bak } & $r=0.311$ & & $r=0.447$ & $r=0.100$ & $r=-0.230$ & $r=-0.242$ & $r=0.212$ & $r=0.253$ \\
\hline & $P=0.005^{*}$ & & $P<0.001^{*}$ & $P=0.381$ & $P=0.044^{*}$ & $P=0.034^{*}$ & $P=0.098$ & $P=0.025^{*}$ \\
\hline \multirow[t]{2}{*}{ bid } & $r=0.364$ & $r=0.447$ & & $r=0.181$ & $r=-0.189$ & $r=-0.331$ & $r=0.149$ & $r=0.116$ \\
\hline & $P=0.001^{*}$ & $P<0.001^{*}$ & & $P=0.110$ & $P=0.100$ & $P=0.003^{*}$ & $P=0.248$ & $P=0.307$ \\
\hline \multirow[t]{2}{*}{ bad } & $r=0.224$ & $r=0.100$ & $r=0.181$ & & $r=-0.005$ & $r=-0.288$ & $r=0.189$ & $r=0.011$ \\
\hline & $P=0.047^{*}$ & $P=0.381$ & $P=0.110$ & & $P=0.962$ & $P=0.011^{*}$ & $P=0.142$ & $P=0.923$ \\
\hline \multirow[t]{2}{*}{ bcl2 } & $r=-0.207$ & $r=-0.230$ & $r=-0.189$ & $r=-0.005$ & & $r=0.237$ & $r=-0.293$ & $r=-0.101$ \\
\hline & $P=0.070$ & $P=0.044^{*}$ & $P=0.100$ & $P=0.962$ & & $P=0.039 *$ & $P=0.022^{*}$ & $P=0.382$ \\
\hline \multirow[t]{2}{*}{ bcl-xl } & $r=-0.437$ & $r=-0.242$ & $r=-0.331$ & $r=-0.288$ & $r=0.237$ & & $r=-0.115$ & $r=-0.159$ \\
\hline & $P<0.001^{*}$ & $P=0.034^{*}$ & $P=0.003^{*}$ & $P=0.011^{*}$ & $P=0.039^{*}$ & & $P=0.376$ & $P=0.168$ \\
\hline \multirow[t]{2}{*}{ AI } & $r=0.146$ & $r=0.212$ & $r=0.149$ & $r=0.189$ & $r=-0.293$ & $r=-0.115$ & & $r=0.501$ \\
\hline & $P=0.258$ & $P=0.098$ & $P=0.248$ & $P=0.142$ & $P=0.022^{*}$ & $P=0.376$ & & $P<0.001^{*}$ \\
\hline \multirow[t]{2}{*}{ PI } & $r=0.207$ & $r=0.253$ & $r=0.116$ & $r=0.011$ & $r=-0.101$ & $r=-0.159$ & $r=0.501$ & \\
\hline & $P=0.068$ & $P=0.025^{*}$ & $P=0.307$ & $P=0.923$ & $P=0.382$ & $P=0.168$ & $P<0.001^{*}$ & \\
\hline
\end{tabular}

$r$, Spearman's correlation coefficient. The positive or negative sign of the Spearman's correlation coefficient $r$ expresses significant $(P<0.05)$ or nonsignificant $(P=0.05$ or $P>0.05)$ positive or negative correlations between two continuous variables.

*indicates the statistically significant correlations $(P<0.05)$.

\section{Relations between bcl2 Family Proteins, Apoptotic Index and Proliferation Index}

The Spearman correlation coefficient test was used to analyze the relations between bcl2 family proteins, apoptotic index and proliferation index (Ki67) (Table 8). The positive or negative sign of the Spearman correlation coefficient $r$ in Table 8 expresses significant $(P<0.05)$ or nonsignificant $(P=0.05$ or $P>0.05)$ positive or negative correlations between two continuous variables. The following significant correlations were found: (a) the expression of bax protein showed significant positive correlation with the expression of bak $(r=0.311$, $P=0.005)$, bid $(r=0.364, \quad P=0.001)$ and bad ( $r=0.224, P=0.047)$ proteins, (b) the expression of bak protein showed significant positive correlation with the expression of bid protein $(r=0.447$, $P<0.001)$ and the proliferation index (Ki67) $(r=0.253, P=0.025)$ proteins and significant negative correlation with the expression of bcl2 protein ( $r=-0.230, P=0.044)$, (c) the expression of bcl-xl protein showed significant negative correlation with the expression of bax $(r=-0.437, P<0.001)$, bak $(r=-0.242, P=0.034)$, bid $(r=-0.331, P=0.003)$ and bad $(r=-0.288, P=0.011)$ proteins and significant positive correlation with the expression of bcl2 protein $(r=0.237, P=0.017)$ and $(d)$ the expression of bcl2 protein showed significant negative correlation with the apoptotic index $(r=-0.293, P=0.022)$ (Table 8).

\section{Correlation with Clinicopathological Parameters}

Using $\chi^{2}$ tests, no significant correlation was found between tumor localization (nodal vs extranodal) or tumor stage (I-IV) and the two major bcl6/CD10/ MUM1/CD138 differentiation immunophenotypic profiles (data not shown).

\section{Discussion}

In the present study, we analyzed the relations between the bcl6/CD10/MUM1/CD138 differentiation immunophenotypic profiles and the status of apoptosis and proliferation in diffuse large B-cell lymphomas. In addition, we analyzed the expression patterns of the bcl2 family proteins bcl2, bcl-xl, 
bax, bak, bad and bid in relation to the apoptotic index and the proliferation index.

In the present study, we found that in diffuse large B-cell lymphomas the germinal center B-cell-like differentiation immunophenotypic profile was significantly correlated with high apoptotic index, high expression of the proapoptotic proteins bax, bak and bid and low expression of the antiapoptotic protein bcl-xl. In addition, the expression of the germinal center B-cell-related bcl6 and CD10 proteins showed significant positive correlation with bax, bak and bid expression and significant negative correlation with bcl-xl expression. Furthermore, we recently reported that the expression of bcl6 and CD10 proteins showed significant positive correlation with apoptotic index. ${ }^{41}$ The aforementioned results, taken together, may be related to findings in various cell lines and lymphoid malignancies suggesting that the expression of the proteins bcl6 and CD10 is associated with increased apoptosis. ${ }^{33-40}$ With respect to the relation between bcl6 and apoptosis, of particular interest are the in vitro studies of Yamochi et $a l^{35}$ and Tang et $a l^{36}$ Indeed, Yamochi et $a l^{35}$ showed that bcl6 overexpression induced apoptosis of CV1 and HeLa cells which was preceded by downregulation of the antiapoptotic genes bcl2 and $b c l-x l$. In addition, Tang et $a l^{36}$ showed that the forkhead transcription factor AFX activates apoptosis by induction of bcl6 which directly binds to and suppresses the promoter of bcl-xl. These findings suggest that the significantly lower expression of the antiapoptotic protein bcl-xl that we found in diffuse large B-cell lymphomas with germinal center B-cell like immunophenotypic profile may be due, at least in part, to downregulation of bcl-xl expression induced by bcl6 overexpression. ${ }^{36}$ With respect to the relation between CD10 and apoptosis, it was suggested that CD10 might degrade cytokines that could play a protective role in $\mathrm{B}$ - and T-cell apoptosis. ${ }^{38}$ This activity may be consistent with the capacity of CD10 to hydrolyze a variety of active peptides, including growth and chemotactic factors. ${ }^{38}$ Thus, it is possible that CD10 participates in the process of selection in the germinal center and the thymus by increasing the threshold of cytokines required to prevent $\mathrm{B}$ - and $\mathrm{T}$-cell apoptosis, respectively. $^{38}$

In the present study, we found that in diffuse large B-cell lymphomas the nongerminal center B-celllike differentiation immunophenotypic profile was significantly associated with low apoptotic index, low expression of the proapoptotic proteins bax, bak and bid and high expression of the antiapoptotic protein bcl-xl. In addition, the expression of the MUM1 protein, which is a main feature of the nongerminal center B-cell-like immunophenotypic profile, ${ }^{12,32}$ showed significant negative correlation with bax and bid expression and significant positive correlation with bcl-xl expression. The aforementioned results, taken together, may be related to findings that activated (nongerminal) diffuse large
B-cell-like lymphomas are characterized by constitutive nuclear factor-Kappa B activity which may upregulate many antiapoptotic nuclear factor-Kappa $B$ target genes such as bcl2, bcl-xl, A1, TRAF1, TRAF2, c-IAP1 and c-IAP2. ${ }^{33,53}$ These findings suggest that the significantly higher expression of the antiapoptotic protein bcl-xl that we found in diffuse large B-cell lymphomas with nongerminal center B-cell-like immunophenotypic profile may be due, at least in part, to upregulation of bcl-xl expression induced by the constitutive nuclear factor-Kappa B activity. ${ }^{33}$ In addition, the IRF4 (MUM1/LSIRF) gene is also a nuclear factorKappa B target ${ }^{33,53,54}$ and this may provide an explanation for the significant positive correlation between MUM1 and bcl-xl expression in the present study. IRF4, a transcription factor that is required for the proliferation of $\mathrm{B}$ and $\mathrm{T}$ lymphocytes, has been suggested to be a mediator of nuclear factorKappa B proliferative responses in activated (nongerminal center) B-cell-like diffuse large B-cell lymphomas. ${ }^{54}$

In the present study, we found that diffuse large B-cell lymphomas frequently express bcl2 family proteins: bax in $92 \%$, bak in $52 \%$, bad in $76 \%$, bid in $56 \%$ and bcl-xl in $60 \%$. These results, taken together with previous findings ${ }^{16,18,20,21,27,41-50}$ showing that diffuse large B-cell lymphomas frequently express bcl2, mcl1, bax and bak proteins, suggest that apoptotic mechanisms mediated by bcl2 family proteins are likely to be involved in the pathogenesis of diffuse large B-cell lymphomas. Interestingly, the present and previous findings ${ }^{16,18,20,21,27,42-50}$ indicate that the expression of bcl2 family proteins is variable and heterogeneous in diffuse large B-cell lymphomas. This is likely to reflect differentially regulated expression of bcl2 family proteins, which may be related to abnormalities in gene structure and/or expression. It is known that variations of bcl2 expression in a part of diffuse large B-cell lymphomas may be ascribed to $t(14 ; 18)$ of bcl 2 to $\operatorname{IgH}$ locus or to amplification of the bcl2 gene genomic locus. ${ }^{3-6,14,16,21}$ The variations in bax, bak and bcl-xl expression in diffuse large B-cell lymphomas may not be related to underlying gene mutations since they were rare in these tumors. ${ }^{50,55,56}$ Interestingly, bad-deficient mice develop, with aging, diffuse large B-cell lymphomas of germinal center origin ${ }^{57}$ suggesting a putative role of bad in the pathogenesis of these neoplasias. Further studies are required to gain insight into the regulation of the expression of the bcl2 family proteins in diffuse large B-cell lymphomas.

In the present study, we found that the apoptotic index was positively correlated with the expression of the proapoptotic proteins bax, bak, bad and bid and negatively correlated with the expression of the antiapoptotic proteins bcl2 and bcl-xl. Thus, the differential expression of bcl2 family proteins may provide an explanation, at least in part, for the variations of the apoptotic index observed in diffuse 
large B-cell lymphomas. ${ }^{41}$ In addition, the proliferation index (Ki67) was positively correlated with the apoptotic index and the expression of the proapoptotic proteins bax, bak, bad and bid and negatively correlated with the expression of the antiapoptotic proteins bcl2 and bcl-xl. These results are in keeping with previous findings that apoptotic and proliferative indices are positively correlated in B-cell lymphomas ${ }^{42,58}$ and with recent data that bcl-xl and bcl2 inhibit cell proliferation. ${ }^{59,60}$ Interestingly, the antiproliferative effects of bcl-xl and bcl2 were related to their ability to enhance $\mathrm{G}(0)$ arrest thereby contributing to cell cycle delay in $G$ (0)-G (1) transition. ${ }^{59}$ Thus, it was suggested that the cell cycle effects result from intrinsic functions of bcl-xl and bcl2. ${ }^{59}$ Furthermore, other apoptosisassociated bcl2 family proteins such as mcl1 may be involved in the regulation of cell proliferation and differentiation by sustaining or inhibiting cell viability at critical points of the cell cycle (review in Craig ${ }^{61}$ ).

The relations between differentiation immunophenotypic profiles and apoptosis status may be relevant to the clinical behavior of diffuse large B-cell lymphomas. Indeed, recent studies reported that (a) the 5-year survival of diffuse large B-cell lymphomas with germinal center B-cell-like immunophenotypic profile was better than that of diffuse large B-cell lymphomas with nongerminal center Bcell-like immunophenotypic profile ${ }^{20,32}$ and (b) the immunoexpression of bcl6 or CD10 proteins was associated with better overall survival whereas expression of MUM1 protein was associated with worse overall survival in diffuse large B-cell lymphomas. ${ }^{8,13,22,28,32}$ In addition, high bax immunoexpression, which was associated with the germinal center B-cell-like immunophenotypic profile in the present study, was found to be related to better 5-year overall survival in diffuse large B-cell lymphomas. ${ }^{48}$ On the basis of the above results, it could be hypothesized that germinal center B-celllike diffuse large B-cell lymphoma may be more susceptible to apoptosis and, as a consequence, may be more sensitive to treatment.

In conclusion, the present study indicates that diffuse large B-cell lymphomas with germinal center B-cell-like immunophenotypic profile are associated with increased apoptosis status, high expression of the proapoptotic proteins bax, bak and bid and low expression of the antiapoptotic protein bcl-xl. In contrast, diffuse large B-cell lymphomas with nongerminal center B-cell-like immunophenotypic profile are associated with decreased apoptosis status, low expression of the proapoptotic proteins bax, bak and bid and high expression of the antiapoptotic protein bcl-xl. In view of previous results ${ }^{20,32}$ showing that the expression of the germinal center B-cell-like differentiation immunophenotypic profile is associated with favorable clinical outcome, it could be hypothesized that germinal center B-celllike diffuse large B-cell lymphoma may be more susceptible to apoptosis and, as a consequence, may be more sensitive to treatment.

\section{Acknowledgements}

This study was supported by the grants Heraklitos (Scholarships for Basic Research) and ELE II/2000 from the Research Comission of the University of Ioannina. We are grateful to Antigoni Christodoulou for her excellent technical assistance.

\section{References}

1 Gatter KC, Warnke RA. Diffuse large B-cell lymphoma. In: Jaffe ES, Harris NL, Stein H, Vardiman JW (eds). World Health Organization Classification of Tumours. Pathology and Genetics of Tumours of the Haematopoietic and Lymphoid Tissues. International Agency for Research on Cancer (IARC) Press: Lyon, 2001, pp 171-174.

2 Pileri SA, Dirnhofer S, Went $\mathrm{P}$, et al. Diffuse large B-cell lymphoma: one or more entities? Present controversies and possible tools for its subclassification. Histopathology 2002;41:482-509.

3 Shaffer AL, Rosenwald A, Staudt LM. Lymphoid malignancies: the dark side of B-cell differentiation. Nat Rev Immunol 2002;2:920-932.

4 Sanchez-Beato M, Sanchez-Aguilera A, Piris MA. Cell cycle deregulation in B-cell lymphomas. Blood 2003;101:1220-1235.

5 de Leval L, Harris NL. Variability in immunophenotype in diffuse large B-cell lymphoma and its clinical relevance. Histopathology 2003;43:509-528.

6 Falini B, Mason DY. Proteins encoded by genes involved in chromosomal alterations in lymphoma and leukaemia: clinical value of their detection by immunocytochemistry. Blood 2002;99:409-426.

7 Berglund M, Enblad G, Flordal E, et al. Chromosomal imbalances in diffuse large B-cell lymphoma detected by comparative genomic hybridization. Mod Pathol 2002;15:807-816.

8 Alizadeh AA, Eisen MB, Davis RE, et al. Distinct types of diffuse large B-cell lymphoma identified by gene expression profiling. Nature 2000;403: 503-511.

9 Rosenwald A, Wright G, Chan WC, et al. The use of molecular profiling to predict survival after chemotherapy for diffuse large B-cell lymphoma. N Engl J Med 2002;346:1937-1947.

10 Wright G, Tan B, Rosenwald A, et al. A gene expression-based method to diagnose clinically distinct subgroups of diffuse large B-cell lymphoma. Proc Natl Acad Sci USA 2003;19:9991-9996.

11 Shipp MA, Ross KN, Tamayo P, et al. Diffuse large Bcell lymphoma outcome prediction by gene-expression profiling and supervised machine learning. Nat Med 2002;8:68-74.

12 Colomo L, Lopez-Guillermo A, Perales $\mathrm{M}$, et al. Clinical impact of the differentiation profile assessed by immunophenotyping in patients with diffuse large B-cell lymphoma. Blood 2003;101:78-84.

13 Lossos IS, Jones CD, Warnke R, et al. Expression of a single gene BCL-6, strongly predicts survival in 
patients with diffuse large B-cell lymphoma. Blood 2001;98:945-951.

14 Fang JM, Finn WG, Hussong JW, et al. CD 10 antigen expression correlates with the $\mathrm{t}(14 ; 18)(\mathrm{q} 32 ; \mathrm{q} 21)$ major breakpoint region in diffuse large B-cell lymphoma. Mod Pathol 1999;12:295-300.

15 Larocca LM, Capello D, Rinelli A, et al. The molecular and phenotypic profile of primary central nervous system lymphoma identifies distinct categories of the disease and is consistent with histogenetic derivation from germinal center-related B-cells. Blood 1998;92: 1011-1019.

16 Skinnider FB, Horsman ED, Dupuis B, et al. Bcl-6 and Bcl-2 protein expression in diffuse large B-cell lymphoma and follicular lymphoma: correlation with 3q27 and 18q21 chromosomal abnormalities. Hum Pathol 1999;30:803-808.

17 Dogan A, Bagdi E, Munson P, et al. CD 10 and BCL-6 expression in paraffin sections of normal lymphoid tissue and B-cell lymphomas. Am J Surg Pathol 2000;26:846-852.

18 King BE, Chen C, Locker J, et al. Immunophenotypic and genotypic markers of follicular center cell neoplasia in diffuse large B-cell lymphomas. Mod Pathol 2000;13:1219-1231.

19 Ree HJ, Yang WI, Kim CW, et al. Coexpression of Bcl-6 and CD 10 in diffuse large B-cell lymphomas: significance of Bcl-6 expression patterns in identifying germinal center B-cell lymphoma. Hum Pathol 2001;32:954-962.

20 Barrans LS, Carter I, Owen GR, et al. Germinal center phenotype and bcl-2 expression combined with the International Prognostic Index improves patient risk stratification in diffuse large B-cell lymphoma. Blood 2002;99:1136-1143.

21 Huang JZ, Sanger WG, Greiner TC, et al. The t(14;18) defines a unique subset of diffuse large B-cell lymphoma with a germinal center B-cell gene expression profile. Blood 2002;99:2285-2290.

22 Ohshima K, Kawasaki C, Muta H, et al. CD10 and Bcl10 expression in diffuse large B-cell lymphoma: CD10 is a marker of improved prognosis. Histopathology 2002;39:156-162.

23 de Leval L, Braaten KM, Ancukiewicz M, et al. Diffuse large B-cell lymphoma of bone: an analysis of differentiation-associated antigens with clinical correlation. Am J Surg Pathol 2003;27:1269-1277.

24 Paulli M, Viglio A, Vivenza D, et al. Primary cutaneous large B-cell lymphoma of the leg: histogenetic analysis of a controversial clinicopathologic entity. Hum Pathol 2002;33:937-943.

25 Kwon MS, Go JH, Choi JS, et al. Critical evaluation of the Bcl-6 expression in diffuse large B-cell lymphoma of the stomach and small intestine. Am J Surg Pathol 2003;27:790-798.

26 Ree HJ, Ohsima K, Aozasa K, et al. Detection of germinal center B-cell lymphoma in archival specimens: critical evaluation of Bcl-6 protein expression in diffuse large B-cell lymphoma of the tonsil. Hum Pathol 2003;34:730-736.

27 Barrans SL, Evans PA, O'Connor SJ, et al. The $t(14 ; 18)$ is associated with germinal center derived diffuse large B-cell lymphoma and is a strong predictor of outcome. Clin Cancer Res 2003;9: 2133-2139.

28 Braaten KM, Betensky RA, de Leval L, et al. BCL-6 expression predicts improved survival in patients with primary central nervous system lymphoma. Clin Cancer Res 2003;9:1063-1069.

29 Tsuboi $\mathrm{K}$, Iida $\mathrm{S}$, Inagaki $\mathrm{H}$, et al. MUM1/IRF4 expression as a frequent event in mature lymphoid malignancies. Leukemia 2000;14:449-456.

30 Natkunam Y, Warnke RA, Montgomery $\mathrm{K}$, et al. Analysis of MUM1/IRF4 protein expression using tissue microarray and immunohistochemistry. Mod Pathol 2001;14:686-694.

31 Linderoth J, Jerkeman M, Cavallin-Stahl E, et al. Nordic Lymphoma Group Study. Immunohistochemical expression of CD23 and CD40 may identify prognostically favorable subgroups of diffuse large B-cell lymphoma: a Nordic Lymphoma Group Study. Clin Cancer Res 2003;9:722-728.

32 Hans CP, Weisenburger DD, Greiner TC, et al. Confirmation of the molecular classification of diffuse large B-cell lymphoma by immunohistochemistry using a tissue microarray. Blood 2003;103:275-282.

33 Shaffer AL, Rosenwald A, Hurt EM, et al. Signatures of the immune response. Immunity 2001;15:375-385.

34 Dent AL, Vasanwala FH, Toney L. Regulation of gene expression by the proto-oncogene BCL-6. Crit Rev Oncol Hematol 2002;41:1-9.

35 Yamochi T, Kaneita Y, Akiyama T, et al. Adenovirusmediated high expression of BCL-6 in CV-1 cells induces apoptotic cell death accompanied by downregulation of BCL-2 and BCL-X (L). Oncogene 1999;18:487-494.

36 Tang TTL, Dowbenko D, Jackson A, et al. The forkhead transcription factor AFX activates apoptosis by induction of the bcl6 transcriptional repressor. J Biol Chem 2002;277:14255-14265.

37 Albagli O, Lantoine D, Quief S, et al. Overexpressed BCL6 (LAZ3) oncoprotein triggers apoptosis, delays S phase progression and associates with replication foci. Oncogene 1999;18:5063-5075.

38 Cutrona G, Leanza N, Ulivi M, et al. Expression of CD10 by human $\mathrm{T}$ cells that undergo apoptosis both in vitro and in vivo. Blood 1999;94:3067-3076.

39 Cutrona G, Tasso P, Dono M, et al. CD 10 is a marker for cycling cells with propensity to apoptosis in childhood ALL. Br J Cancer 2002;86:1776-1785.

40 Morabito F, Mangiola M, Rapezzi D, et al. Expression of CD10 by B-chronic lymphocytic leukemia cells undergoing apoptosis in vivo and in vitro. Haematologica 2003;88:864-873.

41 Bai M, Agnantis NJ, Skyrlas A, et al. Increased expression of the bcl6 and CD10 proteins is associated with increased apoptosis and proliferation in diffuse large B-cell lymphomas. Mod Pathol 2003;16:471-480.

42 Kiberu SW, Pringle JH, Sobolewski S, et al. Correlation between apoptosis, proliferation and bcl-2 expression in malignant non-Hodgkin's lymphomas. J Clin Pathol (Mol Pathol) 1996;49:M268-M272.

43 Gascoyne RD, Krajewska M, Krajewski S, et al. Prognostic significance of Bax protein expression in diffuse aggressive non-Hodgkin's lymphoma. Blood 1997;90:3173-3178.

44 Wheaton S, Netser J, Guinee D, et al. Bcl-2 and bax protein expression in indolent versus aggressive B-cell non-Hodgkin's lymphomas. Hum Pathol 1998;29: 820-825.

45 Winter JN, Andersen J, Reed JC, et al. BCL-2 expression correlates with lower proliferative activity in the intermediate- and high-grade non-Hodgkin's lymphomas: an Eastern Cooperative Oncology Group and 
Southwest Oncology Group cooperative laboratory study. Blood 1998;91:1391-1398.

46 Bairey O, Zimra Y, Shaklai M, et al. Bcl-2, Bcl-X, Bax, and Bak expression in short- and long-lived patients with diffuse large B-cell lymphomas. Clin Cancer Res 1999;5:2860-2866.

47 MacNamara B, Wang W, Chen Z, et al. Telomerase activity in relation to pro- and anti-apoptotic protein expression in high grade non-Hodgkin's lymphomas. Haematologica 2001;86:386-393.

48 Pagnano KB, Silva MD, Vassallo J, et al. Apoptosisregulating proteins and prognosis in diffuse large B cell non-Hodgkin's lymphomas. Acta Haematol 2002; 107:29-34.

49 Sohn SK, Jung JT, Kim DH, et al. Prognostic significance of bcl-2, bax and p53 expression in diffuse large B-cell lymphoma. Am J Hematol 2003;73:101-107.

50 Marini M, D'Alo F, Holaus S, et al. Absence of structural mutations of bak gene in B-cell lymphoma. Haematologica 2002;87:661-662.

51 Bai M, Vlachonikolis J, Agnantis NJ, et al. Low expression of p27 protein combined with altered p53 and Rb/p16 expression status is associated with increased expression of cyclin A and cyclin B1 in diffuse large B-cell lymphomas. Mod Pathol 2001;14: 1105-1113.

52 Bai M, Tsanou E, Agnantis NJ, et al. Expression of cyclin D3 and cyclin E and identification of distinct clusters of proliferative activity and apoptosis status in diffuse large B-cell lymphomas. Histol Histopathol 2003;18:449-457.

53 Davis RE, Brown KD, Siebenlist U, et al. Constitutive nuclear factor KappaB activity is required for survival of activated B cell-like difuse large B cell lymphoma cells. J Exp Med 2001;194:1861-1874.

54 Grumont RJ, Gerondakis S. Rel induces interferon regulatory factor 4 (IRF-4) expression in lymphocytes: modulation of interferon-regulated gene expression by rel/nuclear factor kappaB. J Exp Med 2000;191: 1281-1292.

55 Peng H, Aiello A, Packham G, et al. Infrequent bax gene mutations in B-cell lymphomas. J Pathol 1998;186:378-382.

56 Yamaguchi $\mathrm{H}$, Inokuchi $\mathrm{K}$, Tarusawa $\mathrm{M}$, et al. Mutations of the bclx gene in non-Hodgkin's lymphomas. Am J Hematol 2002;69:74-76.

57 Ranger AM, Zha J, Harada H, et al. Bad-deficient mice develop diffuse large B cell lymphoma. Proc Natl Acad Sci USA 2003;100:9324-9329.

58 Leoncini L, Cossu A, Megha T, et al. Expression of p34(cdc2) and cyclins A and B compared to other proliferative features of non-Hodgkin's lymphomas: a multivariate cluster analysis. Int J Cancer 1999;83: 203-209.

59 Janumyan YM, Sansam CG, Chattopadhyay A, et al. Bcl-xl/bcl-2 coordinately regulates apoptosis, cell cycle arrest and cell cycle entry. EMBO J 2003;22: 5459-5470.

60 Greider C, Chattopadhyay A, Parkhurst C, et al. Bcl-xl and Bcl-2 delay Myc-induced cell cycle entry through elevation of p27 and inhibition of G1 cyclin-dependent kinases. Oncogene 2002;21: 7765-7775.

61 Craig RW. MCL1 provides a window on the role of BCL2 family in cell proliferation, differentiation and tumorigenesis. Leukemia 2002;16:444-454. 